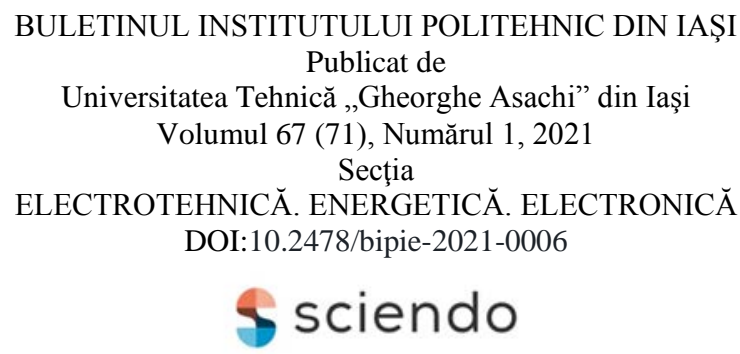

\title{
HYPERCHAOTIC MODULATION FOR SECURE BIOMEDICAL SIGNAL TRANSMISSION
}

\author{
BY \\ VICTOR GRIGORAŞ ${ }^{1, *}$ and CARMEN GRIGORAŞ${ }^{2,3}$ \\ 1“Gheorghe Asachi” Technical University of Iași, \\ Faculty of Electronics, Telecommunication and Information Technology \\ 2“Gr. T. Popa” University of Medicine and Pharmacy of Iaşi, \\ Faculty of Biomedical Engineering \\ ${ }^{3}$ Institute of Computer Science, Romanian Academy, Iaşi Branch
}

Received: October 23, 2021

Accepted for publication: November 30, 2021

Abstract. Nonlinear systems with hyperchaotic dynamical behaviour are studied for applications in complex measurement, modulation and encryption. Unidimensional signals resulting from medical tests can be securely transmitted using chaotic encryption. The present paper analyses synchronization of hyperchaotic systems applied in secure communication. The resulting emitterreceiver pair performance is presented from both dynamic and statistic points of view. Possible application in biomedical signal transmission is analyzed by computer simulations.

Keywords: hyperchaotic dynamics; chaos synchronization; nonlinear systems; signal encryption.

\section{Introduction}

Nonlinear systems can perform complex dynamical behaviors, chaotic and hyperchaotic ones being the most difficult to design for communication applications. Chaotic and hyperchaotic systems were implemented using both

*Corresponding author; e-mail: grigoras@etti.tuiasi.ro

(C) 2021 Victor Grigoraş and Carmen Grigoraş

This is an open access article licensed under the Creative Commons Attribution-NonCommercialNoDerivatives 4.0 International License (CC BY-NC-ND 4.0). 
analog (Sambas, 2015) and digital (Bouraoui, 2013) circuits. Several previously published results show that more complex emitter dynamical behavior ensures better security of the transmitted signal (Grigoraş, 2017; Maqbool, 2017). This justifies the analysis of hyperchaotic systems applied as encryption emitting system, while the synchronizing receiver decrypts the desired signal.

One of the most attractive applications concerns biomedical signal transmission, taking into account that analysis results and medical conclusions have to be protected from unauthorized access (Beck, 2021; Liao, 2021).

The present contribution aims at designing a secure communication system starting from a hyperchaotic emitter, developing a synchronizing receiver and analyzing the performance of biomedical signal transmission using the resulting emitter-receiver pair. The dynamic and statistic properties (Grigoraş, 2015) of the designed system pair are presented based on state equations of the systems. The possibility of applying the proposed communication system to biomedical signal transmission is also highlighted.

The following section is devoted to the design of the nonlinear emitter and synchronizing receiver. The dynamic and statistical analysis results highlight the efficiency of resulting communication system. Simulation results confirming the desired behavior, including the transmission of complex ECG and EEG medical signals, are presented in the third section. The final section highlights resulting conclusions.

\section{System Design}

The proposed analog nonlinear system for emitter implementation is based on the hyperchaotic order four system developed in (Ma, 2013). In order to help designing the synchronizing receiver, the state equations of the emitter are slightly modified compared to the ones in the quoted paper, by adding a supplementary linear term to the last state equation:

$$
\begin{aligned}
& (E:)\left\{\begin{array}{l}
d x_{E} / d t=a \cdot x_{E}-a \cdot y_{E}+w_{E}-y_{E} \cdot z_{E} \\
d y_{E} / d t=-b \cdot y_{E}+x_{E} \cdot z_{E} \\
d z_{E} / d t=d \cdot x_{E}-c \cdot z_{E}+x_{E} \cdot y_{E} \\
d w_{E} / d t=-e \cdot x_{E}-e \cdot y_{E}-f \cdot w_{E}
\end{array}\right. \\
& \operatorname{Out}(t)=x_{E}(t)
\end{aligned}
$$

The state variables of the emitter system are denoted with the index ' $E$ ', in order to easily differ from the receiver state variables that will be denoted with the index ' $R$ '. The state vector of the emitter results: 

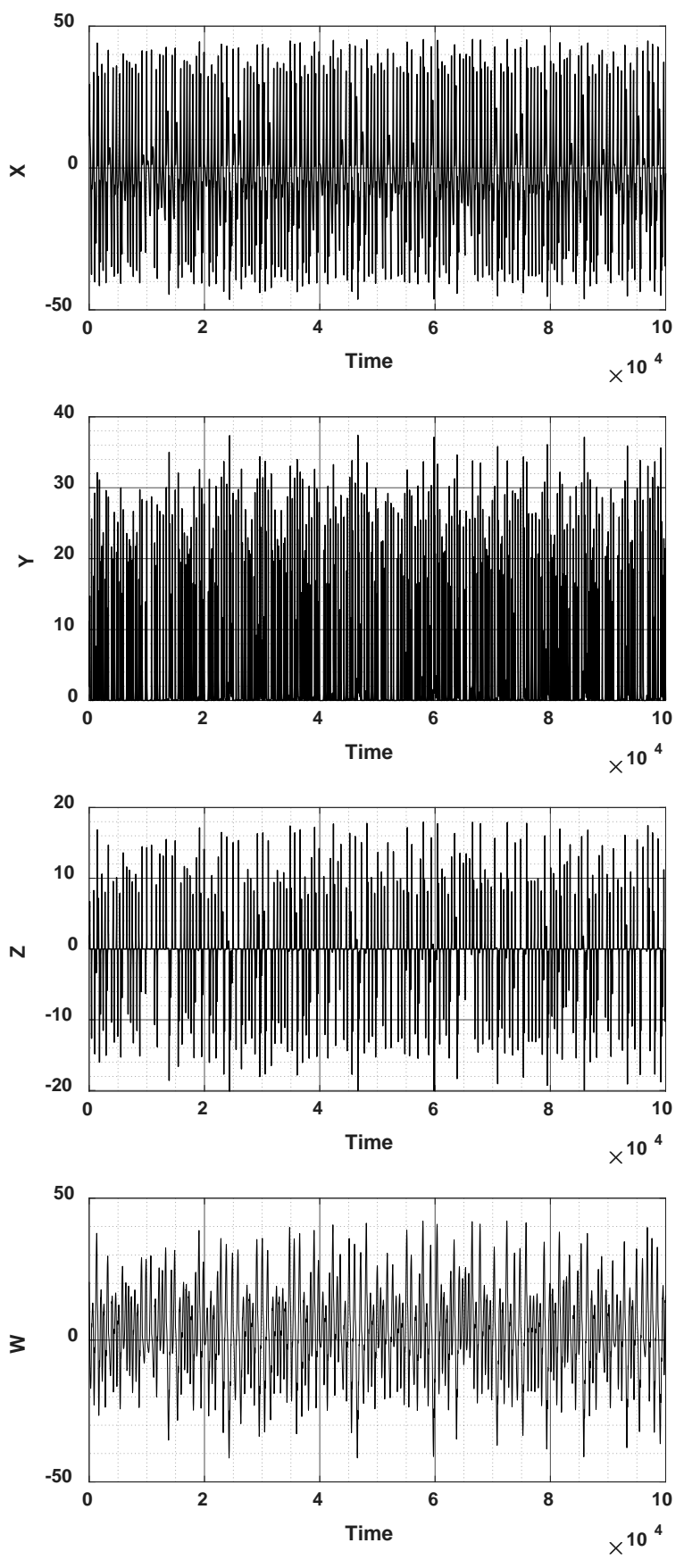

Fig. 1 - Time evolution of the four state variables. 


$$
\mathbf{x}=\left[\begin{array}{lllll}
x_{E} & y_{E} & z_{E} & w_{E}
\end{array}\right]^{T}
$$

The state equations parameters are the ones presented and used in system analysis in (Ma, 2013):

$$
a=0.89 b=9 c=50 d=0.06 e=0.9
$$
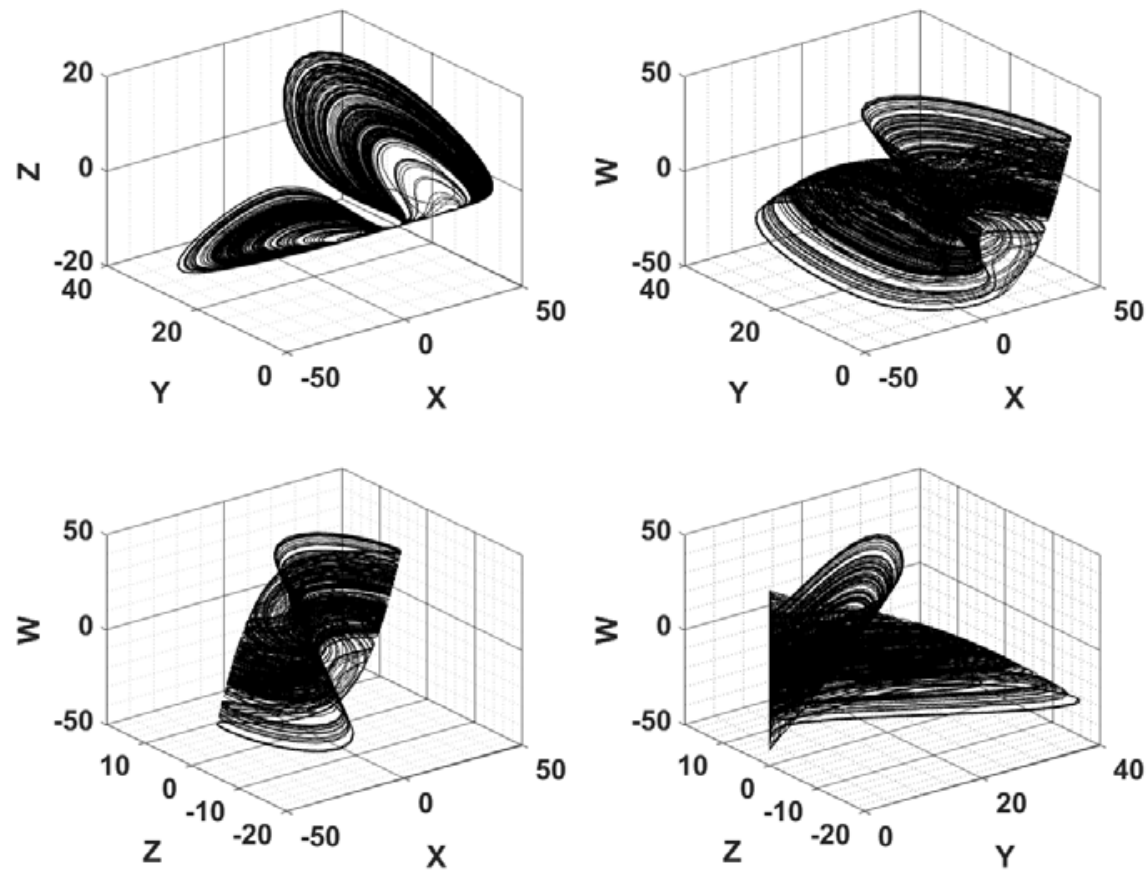

Fig. 2 - Tri-dimensional projections of the emitter attractor.

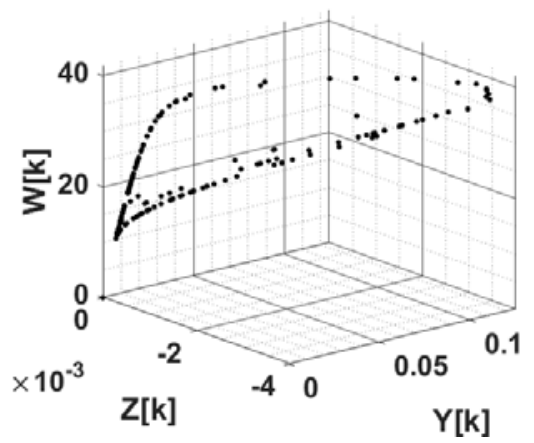

Fig. 3 - Poincare section of the system attractor. 
Because the coefficient in the added term of the fourth equation is relatively small, $f=0.3$, the hyperchaotic behavior of the nonlinear system is not modified, as can be seen in the graphical representations of the example in Fig. 1 of the time evolution of the system state variables. The same aspect can be seen in the examples in Fig. 2, where tri-dimensional projections of the system attractor are similar to the ones in the quoted paper, and in Fig. 3, where examples of Poincare sections suggest hyperchaotic behavior.

The corresponding nonlinear receiver is designed using the emitter partitioning method. From the hyperchaotic emitter, the first state variable, $\operatorname{Out}(t)=x_{E}(t)$, is transmitted and the receiver system is described by copying the other three differential equations:

$$
\begin{aligned}
& \operatorname{Rec}(t)=\operatorname{Out}(t)=x_{E}(t) \\
& (R:)\left\{\begin{array}{l}
d y_{R} / d t=-b \cdot y_{R}+\operatorname{Rec}(t) \cdot z_{R} \\
d z_{R} / d t=-c \cdot z_{R}+d \cdot \operatorname{Rec}(t)+\operatorname{Rec}(t) \cdot y_{R} \\
d w_{R} / d t=-e \cdot y_{R}-f \cdot w_{R}-e \cdot \operatorname{Rec}(t)
\end{array}\right.
\end{aligned}
$$

In the receiver state Eqs. (4) the state variables of the receiver are denoted with the index ' $R$ ' and only the received signal, $\operatorname{Rec}(t)=x_{E}(t)$, keeps the index from the emitter system. The linear part of the receiver state evolution equations, without the received signal to highlight the receiver dynamics are:

$$
\left(R_{\text {Lin }}:\right)\left\{\begin{array}{l}
d y_{R} / d t=-b \cdot y_{R} \\
d z_{R} / d t=-c \cdot z_{R} \\
d w_{R} / d t=-e \cdot y_{R}-f \cdot w_{R}
\end{array}\right.
$$

The linearized receiver, $\left(R_{\text {lin }}\right)$, state Eqs. (5) have the state transition matrix, A:

$$
\mathbf{A}=\left(\begin{array}{ccc}
-b & 0 & 0 \\
0 & -c & 0 \\
-e & 0 & -f
\end{array}\right)
$$

The state transition matrix eigenvalues result negative for positive coefficient values

$$
\left(\begin{array}{lll}
\lambda_{y} & \lambda_{z} & \lambda_{w}
\end{array}\right)^{T}=\left(\begin{array}{lll}
-b & -c & -f
\end{array}\right)^{T}
$$

This ensures the stability of $\left(R_{\text {lin }}\right)$ system, thus fulfilling the necessary condition for synchronization. In order to fulfill a sufficient condition, the error dynamics between emitter and receiver can be used. The error vector does not contain the transmitted signal, $x_{E}(t)$, resulting: 


$$
\boldsymbol{\varepsilon}^{T}=\left[\begin{array}{lll}
\varepsilon_{y} & \varepsilon_{z} & \varepsilon_{w}
\end{array}\right]^{T}=\left[\begin{array}{llll}
y_{E} & z_{E} & w_{E}
\end{array}\right]^{T}-\left[\begin{array}{lll}
y_{R} & z_{R} & w_{R}
\end{array}\right]^{T}
$$

By subtracting the state equations of the receiver (4) from their counterparts of the emitter, the differential equations that model the time evolution of the error result in the form:

$$
(\varepsilon:)\left\{\begin{array}{l}
d \varepsilon_{y} / d t=-b \cdot \varepsilon_{y}+x_{E} \cdot \varepsilon_{z} \\
d \varepsilon_{z} / d t=-c \cdot \varepsilon_{z}+d \cdot x_{E}+x_{E} \cdot \varepsilon_{y} \\
d \varepsilon_{w} / d t=-e \cdot \varepsilon_{y}-f \cdot \varepsilon_{w}-e \cdot x_{E}
\end{array}\right.
$$

Eliminating the transmitted signal $\operatorname{Out}(\mathrm{t})=x_{E}(t)$, from the error differential equations, to highlight only the error dynamical evolution, we obtain the linear differential equations:

$$
\left(\varepsilon_{\text {Lin }}:\right)\left\{\begin{array}{l}
d \varepsilon_{y} / d t=-b \cdot \varepsilon_{y} \\
d \varepsilon_{z} / d t=-c \cdot \varepsilon_{z} \\
d \varepsilon_{w} / d t=-e \cdot \varepsilon_{y}-f \cdot \varepsilon_{w}
\end{array}\right.
$$

Thus, the error dynamic is dominated by the same state transition matrix as the receiver (6) with the same eigenvalues (7) highlighting the exponential decrease of the error to zero, as shown in the graphical example in Fig. 4.

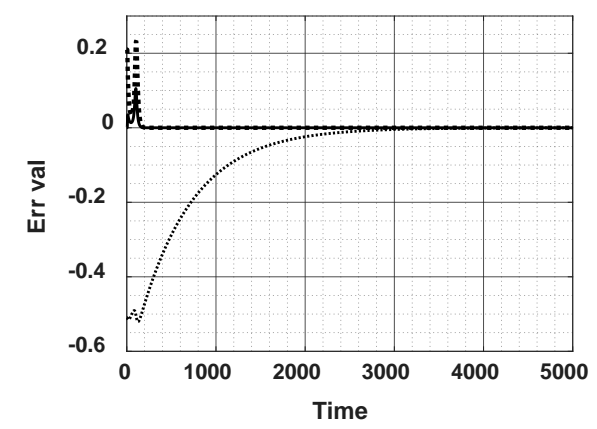

Fig. 4 - Time decreases of $\mathrm{y}, \mathrm{z}$ and $\mathrm{w}$ state synchronization errors.

\section{Biomedical Modulation Results}

In order to use the synchronizing pair $(E)$ - $(R)$, Eqs. (1) and (4), for secure transmission of an analog modulating signal, the direct modulation method is used. The modulating signal, $m(t)$, is added to the first equation of the emitter, leading to a nonlinearly dynamically modulated transmitted signal $\operatorname{Out}(t)=x_{E}(t)$. 


$$
\begin{aligned}
& \left(E_{\mathrm{mod}}:\right)\left\{\begin{array}{l}
d x_{E} / d t=a \cdot x_{E}-a \cdot y_{E}+w_{E}-y_{E} \cdot z_{E}+m(t) \\
d y_{E} / d t=-b \cdot y_{E}+x_{E} \cdot z_{E} \\
d z_{E} / d t=d \cdot x_{E}-c \cdot z_{E}+x_{E} \cdot y_{E} \\
d w_{E} / d t=-e \cdot x_{E}-e \cdot y_{E}-f \cdot w_{E}
\end{array}\right. \\
& \operatorname{Out}(t)=x_{E}(t)
\end{aligned}
$$

The receiver (4) can demodulate the received signal $\operatorname{Rec}(\mathrm{t})$ by subtracting a recovered first state variable, $x_{R}(\mathrm{t})$, at the receiver end from the corresponding emitter one, $x_{E}(\mathrm{t})$.

$$
\begin{aligned}
& x_{R}(t)=\int\left(a \cdot x_{R}-a \cdot y_{R}+w_{R}-y_{R} \cdot z_{R}\right) d t \\
& \tilde{m}(t)=x_{E}(t)-x_{R}(t) \approx m(t)
\end{aligned}
$$
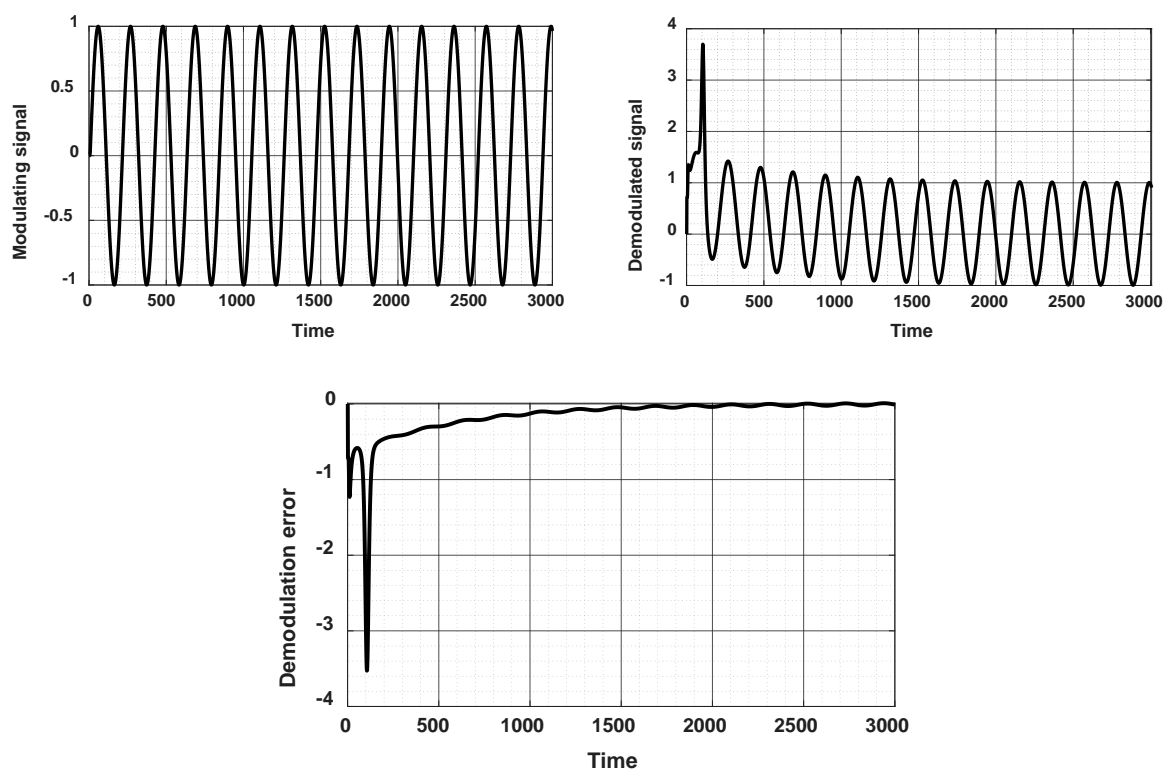

Fig. 5 - Modulation signal, demodulated signal and demodulation error.

The demodulated signal $\widetilde{m}(t)$, approaches the values of the modulating signal, $m(t)$, after the synchronization transient has faded, as suggested in the example in Fig. 5, where a sine modulating signal was used. For wider band signals, the graphical representations in Fig. 6 show an example of transmitting a periodic square shaped signal, highlighting the fact that the larger modulating signal spectrum leads to a somewhat larger demodulating error, especially at the faster variation of the rectangular fronts. 

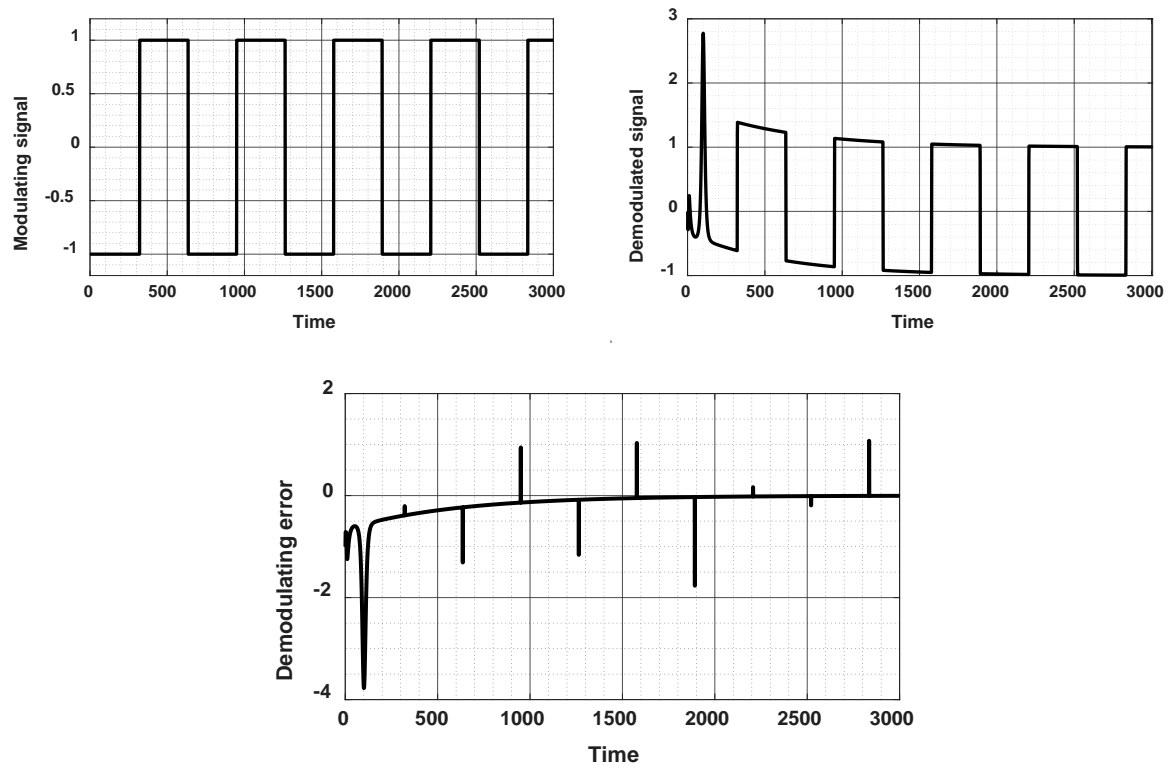

Fig. 6 - Modulating square signal, demodulated signal and demodulation error.

The main application desired for the proposed communication system aims at biomedical signal transmission. One of the tested modulating signals is the ECG signal, as the example in Fig. 7. The more complex modulating signal gives a wider frequency spectrum as shown in Fig. 8.

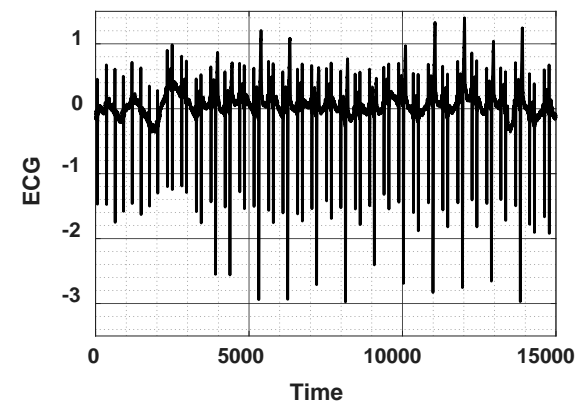

Fig. 7 - ECG signal.

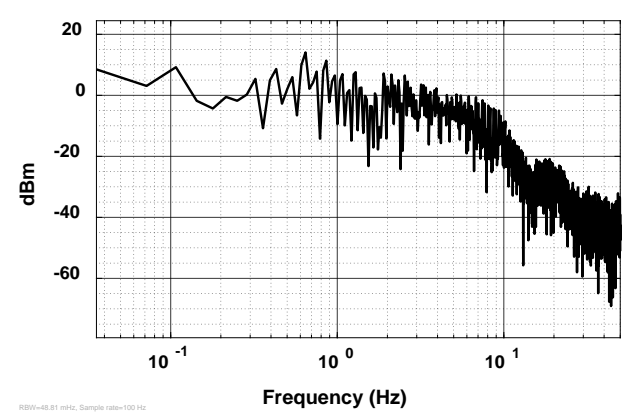

Fig. 8 - ECG spectrum.

Still, the demodulated signal approaches sufficiently well the modulating one, as shown in Fig. 9. The somewhat larger demodulation error in Fig. 10, approaches the rectangular wide spectrum result, but it does not substantially affect the correctness of the desired application. 


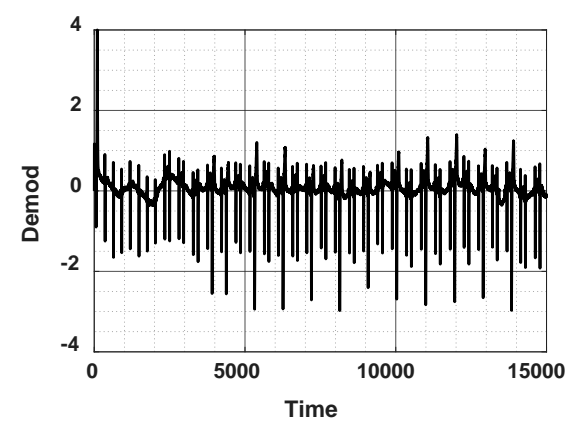

Fig. 9 - ECG demodulated signal.

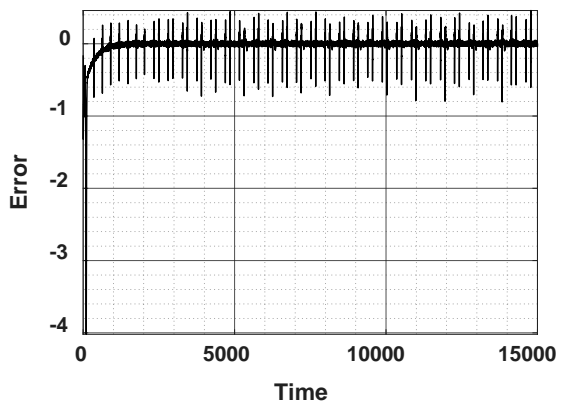

Fig. 10 - ECG demodulation error.

By comparing the transmitted signal in Fig. 11, with the modulating one in Fig. 7 it is obvious that no time variation resemblance exists. A similar comparison can be made between the ECG frequency power spectrum in Fig. 8 and the spectrum of the transmitted signal in Fig. 12. As seen from this statistical approach, even the frequency analysis does not allow an unauthorized receiver to decode the transmitted signal.

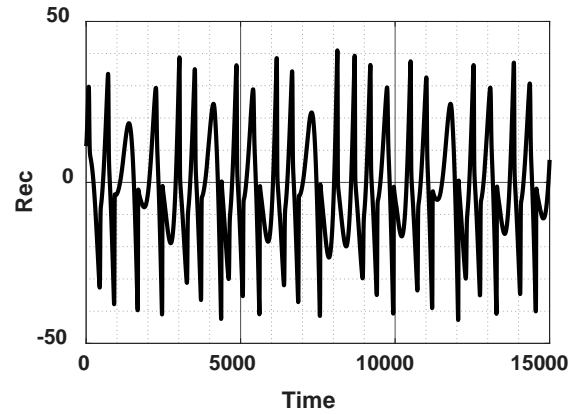

Fig. 11 - ECG transmitted signal

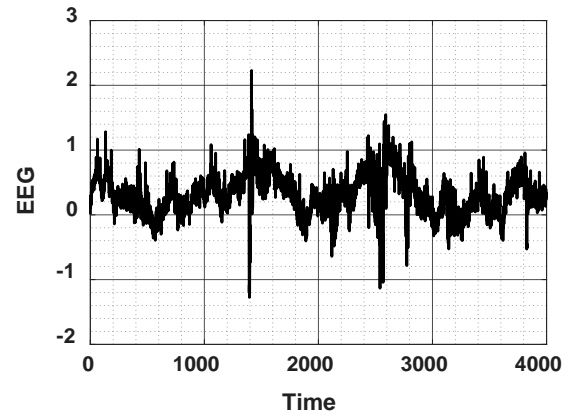

Fig. 13 - EEG modulating signal.

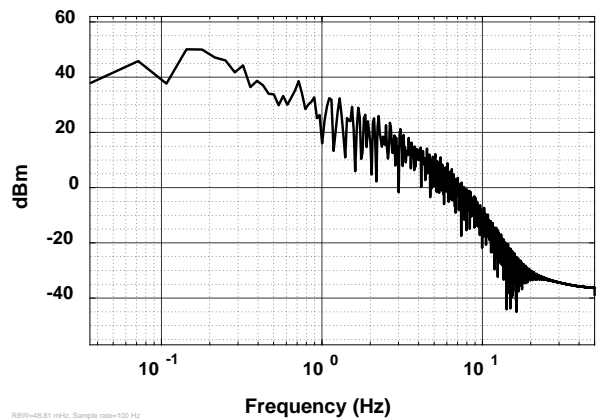

Fig. 12 - ECG transmitted signal spectrum.

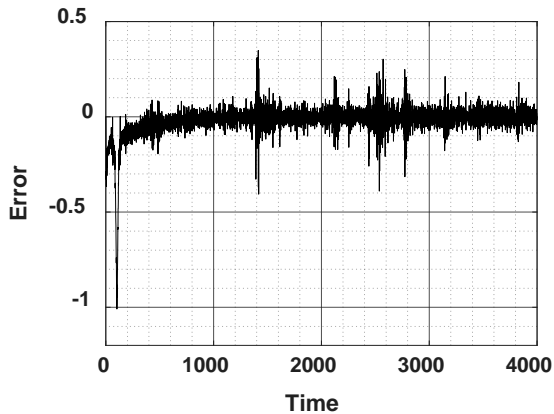

Fig. 14 - EEG demodulation error. 
If a more complex EEG signal is used as a modulating one, as suggested in Fig. 13, the authorized demodulation is reasonably correct as suggested by the demodulation error in Fig. 14.

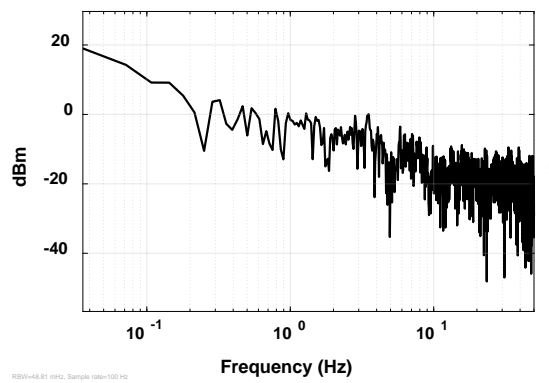

Fig. 15 - EEG spectrum

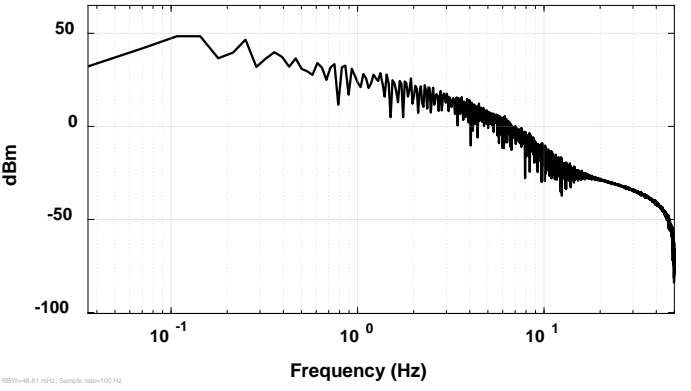

Fig. 16 - EEG transmitted spectrum.

By comparing the frequency power spectra of the EEG modulating signal and transmitted one, the difference is obvious, statistically highlighting the good transmission security ensured by the proposed communication system, even in the case of more complex biomedical modulating signals.

\section{Conclusion}

The present contribution concentrates on designing an analogue emitterreceiver pair based on modulation using hyperchaotic synchronization. The emitter development starts from a previously published hyperchaotic system, with slight modifications aiming at a simpler design of the synchronizing receiver. The dynamical behavior of the modified emitter is detailed using computer simulations, highlighting that the hyperchaotic behavior of the initial system is preserved. The synchronizing receiver is designed using the emitter partitioning method and both synchronization and external signal modulation are shown to function correctly. Even complex unidimensional biomedical signals are transmitted without error, after the synchronization transient has faded. Shown simulations are oriented towards EKG and EEG signals. Better methods for securely transmitting bidimensional medical signals require further research.

\section{REFERENCES}

Beck N., Zuo S., Sigg S., BCG ECG-Based Secure Communication for Medical Devices in Body Area Networks, IEEE International Conference on Pervasive Computing and Communications Workshop, 22 Mar 2021 - 26 Mar 2021, 207-212.

Bouraoui H., Kemih K., Senouci A., Ghanes M., Secure Communication Circuit Simulation Using VHDL-AMS, Proceedings of The first International Conference on Nanoelectronics, Communications and Renewable Energy 2013. 
Grigoraş V., Grigoraş C., Dynamic and Statistic Analysis of a Simple Chaotic Generator, 12th International Symposium on Signals, Circuits and Systems (ISSCS2015), 2015, Iaşi, Romania.

Grigoraş C., Grigoraş V., Complex Dynamics in Hysteretic Nonlinear Oscillator Circuit, Proceedings of the Romanian Academy - Series A Mathematics, Physics, Technical Sciences, Information Science, 18, 4, Oct. Dec. 2017, 370377.

Liao T.-L., Chen H.-C., Peng C.-Y., Hou Y.-Y., Chaos-Based Secure Communications in Biomedical Information Application, Electronics 2021, 10, 359, https://doi.org/10.3390/electronics10030359.

Ma J., Yang Y., Hyperchaos Numerical Simulation and Control in a 4D Hyperchaotic System, Discrete Dynamics in Nature and Society, Volume 2013, Article ID 980578, 226-243, 2013.

Maqbool S., Nisar A., Aslam M., Martinez Enriquez A.M., Simultaneous Encryption and Compression of Digital Images Based on Secure-JPEG Encoding, DOI: 10.1007/978-3-319-39393-3_15.

Sambas A., Mamat M., Sanjaya M., Salleh Z., Susilawati Mohamad F., Secure Communications Based on the Synchronization of the New Lorenz-like Attractor Circuit, Advanced Studies in Theoretical Physics, 9, 2015, 8, 379394, http://dx.doi.org/10.12988/astp.2015.5228.

\section{MODULAŢIA HIPERHAOTICĂ PENTRU TRANSMITEREA SECURIZATĂ A SEMNALELOR BIOMEDICALE}

\section{(Rezumat)}

Sistemele neliniare cu o comportare dinamică hiperhaotică sunt studiate pentru aplicații în măsurări complexe, modulaţie şi criptare. Semnalele unidimensionale rezultate din analizele medicale pot fi transmise securizat folosind criptarea haotică. Lucrarea prezentă analizează sincronizarea hiperhaotică aplicată în comunicații securizate. Performanţa perechii emiţător-receptor este prezentată atât din punct de vedere dinamic cât şi statistic. Posibilitatea de aplicare în transmiterea semnalelor biomedicale este analizată prin simulări pe calculator. 